\title{
Desigualdade nas nações avançadas e periféricas: uma visão do liberalismo nos Estados Unidos e na Índia
}

Inequality in the Central and Peripheral Nations: A Vision of the Liberalism in the United States and India

\author{
Rodrigo Galvão Pinho Lins ${ }^{1}$
}

\section{RESUMO}

O presente trabalho tem, como objetivo, estudar a relação da globalização com a desigualdade nos países centrais e periféricos. Para tanto, os Estados Unidos e a Índia são apresentados como estudo de caso. São observados diferenças entre nações ricas e pobres, assim como o fosso entre a própria população dentro das fronteiras. Chega-se à conclusão de que um governo mais atuante pode dirimir tais desigualdades.

Palavras-chave: Globalização; Estados Unidos; Índia.

\begin{abstract}
The present work aims to study the relation of globalization with inequality in the central and peripheral countries. To this end, the United States and India are presented as case study. Differences between rich and poor nations are observed, as well as the gap between the population itself within the borders. The conclusion is that a more active government can solve such inequalities.
\end{abstract}

Keywords: Globalization; United States; India.

\section{As práticas liberais e suas consequências em país do "centro"}

Os países que formam o "centro" das Relações Internacionais majoritariamente os Estados Unidos e os membros da União Europeia - adotaram a ideia da economia liberal guiada pelo mercado como a verdadeira "estrada para o desenvolvimento".

Beneficiando-se de um poder de produção industrial já mais elevado que o resto do mundo, esses países buscam novos mercados para seus produtos. Apesar disso, os problemas de suas práticas, como a desigualdade, não são relegados apenas a países estrangeiros. Os seus próprios cidadãos já sofrem com isso.

\footnotetext{
${ }^{1}$ Mestrando em Ciência Política (Universidade Federal de Pernambuco) e bolsista do CNPq. Recife, Brasil.
} 
Os Estados Unidos, desde que atingiram o status de superpotência, defendem as ideias de livre-mercado e estado mínimo. Essa defesa, no entanto, passa a ser cada vez mais questionável. As consequências da ideologia de acúmulo de riqueza são bem apresentadas por Stiglitz (2013). Ele lembra que, apesar de a sensibilidade sobre a desigualdade ter aumentado a partir da crise financeira iniciada em 2008, esse problema já vinha sendo construído há, aproximadamente, 30 anos, com duas principais causas os rent-seeking, que buscam aumentar sua parcela de riqueza sem criar riqueza, e as forças abstratas do mercado. Os Estados Unidos passaram a ser um país dividido, com pequena parcela de pessoas que formam os mais ricos, uma grande classe de pobres e uma classe média que está cada vez mais sendo "espremida". Segundo dados levantados por Stiglitz (2013), em 2007, a renda dos 0,1\% mais ricos dos Estados Unidos tinha tamanho 220 vezes maior do que a média dos 90\% mais baixos. Há, nesse país, o problema da "Armadilha de Pobreza", em que a dificuldade enfrentada pelos pobres vai além das oportunidades já escassas de educação e emprego, começando com má nutrição e exposição a ambientes hostis à saúde.

Fazendo um recorte entre os anos de 1950 e 1970, e outro entre os anos de 1980 e 2000, Stiglitz explica que as diferentes políticas adotadas pelo governo federal, em cada um desses dois recortes, têm grande influência nessa desigualdade. Apesar de defender o estado mínimo, no primeiro período, os Estados Unidos faziam uso de ferramentas que tentavam dirimir a situação das classes mais baixas, como acesso à educação superior e sistema de taxação. 0 papel do governo na redistribuição da riqueza de um país e na luta para tentar melhorar a condição de vida dos mais pobres, fica claro, é de extrema importância. Ao defender a política de mercado, o credo liberal busca alcançar o principal fim de sua existência: o já mencionado acúmulo de riqueza. Mas essa riqueza, no atual formato da política norte-americana, só é alcançada para os que já são ricos. Os tomadores de decisões inverteram a lógica da divisão das parcelas de riqueza. Ao invés de receberam uma maior parcela por terem criado condições para que a riqueza como um todo aumentasse - o que poderia significar um aumento também para os de classes mais baixas - eles criaram ferramentas para ter maior participação, tomando daqueles mais pobres (esses são os mencionados rent-seeking). A desigualdade pode ser arrefecida por meio de imposto progressivo e políticas de despesas 
balanceadas, incentivos privados e retorno social em alinhamento. Da forma pensada pelo liberalismo clássico, a economia moderna seria regulada apenas pelo próprio mercado. Dessa forma, ele seria o responsável por fazer com que cada representante do setor privado fosse recompensado pelo papel que seu trabalho apresenta no âmbito social. No entanto, as falhas de mercado "põem em xeque" a distribuição equivalente de riqueza (ou até mesmo uma distribuição suficiente, como apresentada por Frankfurt em

1987). É preciso ter em mente que, ao contrário da ideia de um mercado que se autogoverna e que traz, como efeito, bem-estar para a sociedade como um todo, os empresários liberais têm, como grande objetivo, o lucro. E, para tanto, atuam como podem para que o mercado não funcione corretamente ou, como coloca Stiglitz (2013), que ele funcione apenas "para eles". 0 resultado de toda essa prática é um jogo de soma negativa. Com a forte influência do lobby no sistema político norte-americano, reformas que poderiam dar melhores condições para um crescimento econômico socialmente equilibrado são barradas por grupos de interesses específicos. A insegurança econômica, somada à de saúde mental e até física, apontadas por Stiglitz (2013), levam a questionar a ideia de um país completamente desenvolvido, de acordo com a perspectiva de desenvolvimento como liberdade de Sen (2010).

\section{A globalização e o impacto nos países em desenvolvimento}

Devido aos números estatísticos do desempenho da economia mundial nos últimos 25 anos do século passado, os defensores da globalização argumentam que ela ajudou a acelerar o ritmo de crescimento em todo o mundo, combateu a pobreza e a desigualdade. Mas a mesma globalização excluiu um grande e crescente número de pessoas do desenvolvimento. 0 movimento de globalização criou dois sérios tipos de desigualdade: a primeira se dá entre a força da economia dos países de centro comparado aos países periféricos; a segunda, dentro das próprias fronteiras dos países em desenvolvimento.

\section{Desigualdade entre nações}


A globalização serviu para internacionalizar as práticas dos países liberais e, consequentemente, exportar o modelo econômico para os países em desenvolvimento. Dessa forma, tais Estados passaram a impor os mesmos ideais aos países periféricos por meio de controle de importantes instituições internacionais, como o Banco Mundial e o Fundo Monetário Internacional (FMI). Assim, os países com sistemas capitalistas mais desenvolvidos forçaram os países em desenvolvimento a seguir a "cartilha" oferecida pelo centro. Com mercados abertos e políticas pro-business, as nações da periferia foram incluídas no desenvolvimento econômico predatório. O próprio Celso Furtado (1976) explica que a partir da "tutela política" americana do pós-guerra a "civilização ocidental" passou a ter mais facilidade para realizar manobras a seu favor. A evolução da economia industrial se apresentou sob dois fluxos de inovações: a de técnicas produtivas e o de bens finais de consumo (FURTADO, 1976, p. 90 e 91). Enquanto a transferência da segunda é simples e beneficia os países centrais, o da primeira se apresenta de forma mais complexa. Assim, países periféricos, em sua maioria, permanecem exportadores de produtos com baixo valor agregado e importadores de bens finais de consumo. Amsden (2007) também relata que os países capitalistas, sob a chancela dos Estados Unidos e Inglaterra, impuseram a desregulamentação econômica nos países em desenvolvimento antes mesmo que os produtos de tais países pudessem entrar em seus mercados. A indústria ainda inicial era, dessa forma, destruída, já que as multinacionais eram "construídas e pertenciam a investidores estrangeiros". "Markets, prices, and political control were the hallmarks of how America operated throughout the last half of the twentieth century" (AMSDEN, 2007, p. 5). Nayyar ratifica: "The strong have the power to make the rules and the authority to implement the rules. In contrast, the weak can neither set nor invoke the rules". (NAYYAR, 2006, p. 7).

Ha-Joon Chang (2004) faz um exercício elaborado ao apresentar e desmistificar o papel que as ações e instituições defendidas hoje pelo Consenso de Washington exerceram no desenvolvimento dos países agora industrializados. Citando nominalmente alguns deles, o autor mostra que, no período de desenvolvimento, eles só lograram sucesso por irem contra as chamadas "boas políticas" que hoje pregam. A indústria nascente foi defendida pelo protecionismo do fim do século 18 ao início do século 20. "É particularmente interessante notar que muitos intelectuais e políticos 
norte-americanos, no período de catch-up do país, compreenderam claramente a inconveniência da teoria do livre-comércio" (CHANG, 2004, p. 63). Algumas posições dos países industrializados, buscando se beneficiar no mercado internacional, ficam bastante claras. As fronteiras nacionais, tão ignoradas para o fluxo de capital e de comércio, tornam-se barreiras intransponíveis para o fluxo de tecnologia e de trabalhadores. Isso implica dizer que os países capitalistas podem ter acesso a novos mercados para seus produtos, mas que suas tecnologias não podem ser compartilhadas e que suas empresas não podem empregar trabalhadores estrangeiros.

\section{Desigualdade dentro dos países em desenvolvimento: um olhar sobre a Índia}

Os problemas são ainda mais sensíveis nos países em desenvolvimento. Nos periféricos, a abertura para o capital estrangeiro e a liberalização da economia não representaram, necessariamente, melhor condição de vida para os mais pobres. Como mostram Datt e Ravaillon (2002), a diferença quantitativa de pobreza entre as áreas rurais e urbanas tem crescido no período pós-reforma. Em um estudo comparativo entre os dois períodos, com dados que mostram crescimento em dois tempos (1980-1990 e 1990-2000), Bhattacharya e Sakthivel (2004) argumentam que as reformas liberais tiveram impacto direto no crescimento desigual do país. Na década imediatamente anterior às modificações, apenas três dos 17 Estados estudados tiveram crescimento significativamente inferior ao da Índia (5,6\%): Assam $(3,91 \%)$, Kerala $(4,5 \%)$ e Andhra Pradesh (4,81\%). Já no período de 1990-2000, esse número mais do que dobrou. Entre os que cresceram, Gujarat merece destaque. Como um Estado majoritariamente industrial, ele saltou de 5,71\% no primeiro período para 8,28\% no segundo. A Índia teve crescimento mais modesto, de apenas 0,43 pontos percentuais.

O país vive um paradoxo: de acordo com o Banco Mundial (2013), o país é a quarta maior economia do mundo, ficando atrás apenas dos Estados Unidos, China e Japão. A nova política econômica criou novos setores, como o de software, que cresceu a uma taxa média anual de 8,1\%. Sua receita passou de US\$ 197 milhões em 1990 para US\$ 8 bilhões em 2000 (GUHA, 2008). Mas, se por um lado. a economia do país se mostra arrojada, outra realidade causa preocupação. Ao todo, mais de 560 milhões de pessoas vivem com menos de US\$1,25/dia na Índia - o pior resultado em todo o mundo. No país, 
a comparação já mencionada sobre a área rural e os centros urbanos faz com que a disparidade seja facilmente percebida. Também na Índia, o Estado desempenha papel de destaque na desigualdade que vem se alargando. Como Guha (2008) coloca: “One reason for the continuing poverty is the government's poor record in providing basic services such as education and health care" (GUHA, 2008, p. 693).

As áreas rurais, que caracterizam a maior parte da pobreza indiana, não tiveram os problemas que já existiam do período pré-reforma resolvidos. “O 'fardo do passado' de pobreza e desigualdade", como Metcalf e Metcalf (2013, p. 291) colocam, "ainda pesa sobre muitos povos da Índia”. A educação é um exemplo claro. Em empregos não relacionados com agricultura - ou seja, os que oferecem maiores salários - é exigida educação mais completa. Mas essa educação não é oferecida nessas áreas necessitadas. Além disso, dados da Unesco (2006) mostram que entre 2000 e 2004, 34,6\% dos analfabetos do mundo eram indianos. A China, que aparece em segundo lugar, é "casa" de 11,3\% dos iletrados do mundo. A educação também serve para mensurar a desigualdade existe entre os homens e mulheres. Em levantamento apresentado por Pal e Ghosh (2007), notam-se, não só as diferentes realidades na educação urbano-rural, mas também que a mulher segue sendo vista como inferior ao homem, mesmo nas áreas urbanas. Enquanto 75,85\% dos homens eram alfabetizados, em 2001, apenas 54,16\% das mulheres sabiam ler e escrever.

\section{Considerações Finais}

A riqueza de um país não se converte, necessariamente, em bem-estar para todas as parcelas da sociedade. Como foi possível ver, tanto os Estados Unidos, considerado desenvolvido, como a Índia, ainda apontada como em desenvolvimento, sofrem de um mal comum: uma política econômica que prega o acúmulo de riqueza e, assim, apresentam clivagem crescente entre ricos e pobres. Sob a bandeira do ideário liberal, não é possível vislumbrar desenvolvimento mais completo como definido por Sen (2010) e Nayyar (2006). Ao contrário, é preciso que haja maior coexistência entre o privado e o público. Na Índia, o governo parece ter ficado ciente dessa situação. Em 2005, com o Rural Employment Guarantee Act foi garantido cem dias de trabalho por ano, com o pagamento de, pelo menos, um salário mínimo, para um membro de cada 
família. Nos Estados Unidos, o governo Obama passou a se preocupar com questões sociais como saúde e educação. Leis como Health Care and Education Reconciliation Act e o Patient Protection and Affordable Care Act são exemplos disso. Em suma, o papel do Estado é importante para "dentro" e para "fora" do país. Para as desigualdades internas de um país, apenas o governo tem a capacidade de construir novas políticas com o objetivo de abrandar os transtornos sofridos pelos pobres. No contexto internacional, somente os Estados-nações são construtores de regras e normas, ainda que dentro de organizações e, portanto, também devem ter seu papel reconhecido. Nayyar é categórico na conclusão de seu artigo: "in the pursuit of development, the importance of public action cannot be stressed enough. It must be an integral part of development strategies" (NAYYAR, 2006, p. 21). 0 caso da Índia é um forte exemplo do impacto das ações políticas no bem-estar da população. Embora seja importante compreender a rica história do país para poder ter observação mais completa sobre as clivagens sociais haja vista a exclusão pelo sistema de castas, o destrato com as mulheres e o alto índice de corrupção - foi possível encontrar uma relação entre a política econômica e comercial com características liberais e o aprofundamento dos problemas sociais.

Por fim, é importante apontar as restrições do presente trabalho. 0 pequeno número de casos (dois) impede que a hipótese levantada aqui seja generalizada para todos os países desenvolvidos e em desenvolvimento. Com caráter mais explicativo, o estudo se apresenta como um "pontapé inicial" para um futuro trabalho mais aprofundado.

\section{Referências bibliográficas}

AMSDEN, Alice H. Escape from Empire: the developing world's journey through heaven and hell. Cambridge: The MIT Press. 2007.

BHATTACHARYA, B. B.; SAKTHIVEL, S. Regional Growth and Disparity in India: a comparison of pre and post-reform decades. In: Economic and Political Weekly, vol. 39, n. 10, pp. 1071-1077, mar. 6, 2004. 
HANG, Ha-Joon. Chutando a Escada: a estratégia do desenvolvimento em perspectiva comparada. São Paulo: Editora Unesp. 2004.

China, India, and the Global Economy. World Bank and Institute of Policy Studies. 2007.

DATT, G.; RAVAILLON, M. Is India's economic growth leaving the poor behind?. In: Journal of Economic Perspectives, v. 16, n. 3, p. 89-108. 2002.

FURTAD0, Celso. Prefácio à Nova Economia Política. Rio de Janeiro: Editora Paz e Terra. 1976.

FRANKFURT, Harry. Equality as a Moral Ideal. In: Ethics, Vol. 98, n. 1, p. 21-43. 1987.

GUHA, Ramachandra. India after Gandhi: the history of the world's largest democracy. Harper USA II. 2008.

METCALF, Barbara D. e METCALF, Thomas R. História Concisa da Índia Moderna. São Paulo: Edipro. 2013.

NAYYAR, Deepak. Development through Globalization?, UNU-Wider. 2006.

PAL, Parthapratim; GHOSH, Jaytay. Inequality in India: a survey of recent trends. In: DESA Working Paper N. 45. 2007.

SEN, Amartya. Desenvolvimento como Liberdade. São Paulo: Companhia das Letras. 2010.

STIGLITZ, Joseph E. The Price of Inequality: how today's divided society endangers our future. WW Norton. 2013.

WORLD BANK DATA. Em: http://data.worldbank.org/ 